\title{
Sustentabilidade no setor hoteleiro: desafios no gerenciamento de resíduos sólidos em uma pousada de Belo horizonte/MG
}

Sustainability in the hotel sector: challenges in the management of solid waste in a hotel of Belo Horizonte / MG

\author{
Ana Paula Moreira Venturatto Matos', Mario Luiz Trevisan"
}

\begin{abstract}
RESUMO
A gestão dos resíduos sólidos não é aplicada de forma eficiente nos meios de hospedagem no Brasil, observando-se muitas irregularidades em relação ao gerenciamento dos resíduos sólidos. Um ótimo método para a mudança desta realidade, pensando na conservação no âmbito ambiental, social e econômico, é por meio da educação ambiental, a qual busca sensibilizar a todos no que diz respeito à importância de se aplicar o gerenciamento dos resíduos corretamente, de forma que promova a redução, o reaproveitamento e a reciclagem em todos os meios de produção e na rotina dos cidadãos. Diante destes desafios, o presente trabalhou buscou realizar um estudo de caso em uma pousada de Belo Horizonte/MG a fim de aplicar a educação ambiental aos funcionários e propor medidas de boas práticas no gerenciamento de resíduos sólidos no local. No decorrer deste estudo de caso, foram desenvolvidas atividades ambientalmente sustentáveis, principalmente relacionadas aos resíduos, e ao final diagnosticou-se que apesar do estabelecimento promover a destinação correta dos resíduos, os próprios funcionários não estavam aderindo à ideia da forma correta, o que implica que a educação ambiental aplicada durante o estudo de caso foi relevante para o aumento da percepção ambiental de todos, acerca do assunto trabalhado.
\end{abstract}

Palavras-chave: Educação Ambiental; Gerenciamento de resíduos sólidos; setor hoteleiro; sustentabilidade

\section{ABSTRACT}

The management of solid waste is not efficiently applied in the lodging facilities in Brazil, and there are many irregularities in relation to solid waste management. A great method to change this reality, thinking about environmental, social and economic conservation, is through environmental education, which seeks to raise awareness among all about the importance of applying waste management correctly, in a way which promotes the reduction, reuse and recycling in all means of production and in the routine of citizens. Faced with these challenges, the present work sought to carry out a case study in a hotel in Belo Horizonte/MG in order to apply environmental education to employees and propose measures of good practices in the management of solid waste in the place. In the course of this case study, environmentally sustainable activities were developed, mainly related to solid waste, and in the end it was diagnosed that despite the establishment promoting the idea about the correct disposal of waste, the employees themselves were not adhering to the idea correctly, which implies that the environmental education applied during the case study was relevant to the increase of the environmental perception of all, about the subject worked.

Keywords: Enviromental Education; Sustainability; Solid waste management

\section{INTRODUÇÃO}

A preocupação com a conservação e preservaçáo da natureza tem crescido muito nos últimos tempos. Prova disto é que atualmente existem diversas tendências e ideias sustentáveis e inteligentes em prol do equilíbrio e manejo do meio ambiente, tais como: uso de energia limpa, logística reversa, agricultura orgânica, o reaproveitamento do lixo e a reciclagem (SINGH et al., 2014; ONUBR, 2018). No entanto, não são todas as pessoas, organizaçôes e empreendimentos que são capazes de assumir os reais danos ambientais que causam à

'Graduação em Ciências Biológicas (Licenciatura e Bacharelado) Universidade Federal de Santa Maria e Universidade Aberta do Brasil. anapaulamvm@yahoo.com.br

"Graduação em Engenharia Elétrica pela Universidade Federal de Santa Maria, Santa Maria - RS, Brasil. eletroduto@gmail.com 
natureza (CORRÊA et al, 2014), uma vez que toda atividade humana, independente da sua proporção, acaba degradando de alguma forma o ambiente, causando impactos negativos reversíveis ou não, como por exemplo, o destino incorreto dos resíduos sólidos e o acúmulo do lixo (SANTOS e MATSCHUCK, 2015; PRADO et al., 2015). O que fazer com todo o lixo gerado pela população mundial hoje? Há espaço para todo lixo descartado por cidadão? Estes são alguns questionamentos polêmicos e que ainda não apresentam uma solução definitiva.

Toda atividade econômica e em toda rotina de cada cidadão, ocorre a utilização de resíduos sólidos e a consequente geração do lixo, o qual, se não gerenciado e tratado, pode degradar a natureza e causar prejuízos ambientais e sociais (PERUCHIN, 2015; CARVALHO et al., 2009). Nesta perspectiva, muitas cidades, instituiçôes e estabelecimentos, como hotéis e pousadas, estão buscando trabalhar a sustentabilidade ambiental e social e se adequar às leis ambientais do Brasil e/ou criar normas ambientais internas que busquem aplicar alguma atividade que visa ao desenvolvimento sustentável, melhorando assim a sua imagem e promovendo o que chamamos de "Marketing Verde" (CARVALHO et al.,2009).

O turismo é uma atividade importante do ponto de vista social, cultural e ambiental, entretanto se náo bem administrado e aplicado, ele pode degradar a natureza. O setor hoteleiro, que lida com o turismo, mais especificamente o turismo sustentável, tem encontrado algumas soluçóes para degradar menos o ambiente e inclusive atrair e satisfazer os turistas ambientalmente corretos (MINISTÉRIO DO TURISMO, 2016). Estas soluções e alternativas estáo em alta consideração atualmente, pois o sucesso do setor hoteleiro depende da conservaçáo da natureza de diversos destinos turísticos.

Os mais expressivos aspectos e impactos ambientais que o setor hoteleiro apresenta são: $\mathrm{O}$ uso da água e energia elétrica; a geração e consumo de resíduos sólidos; efluentes orgânicos; emissão de CFC e a contaminação do solo e da água (CORRÊA et al., 2014). Dentre estes aspectos um muito preocupante relaciona-se ao destino correto dos resíduos sólidos que compóe o lixo.

A preocupação com a geração e o destino correto do lixo, melhor dizendo, resíduos sólidos, gerados pela sociedade, se torna cada vez mais uma ação frequente, preocupante e necessária. Se boa parte da população aderir à reciclagem, reaproveitar melhor os produtos e materiais; destinar e fiscalizar corretamente os resíduos sólidos; consumir conscientemente; exigir a conservação dos recursos naturais; cuidar e manter em equilíbrio dinâmico o meio ambiente (natural e artificial); dentre outros, o desenvolvimento sustentável poderá não ser apenas uma teoria, mas sim uma prática usual (LIMA e COSTA, 2016). Mas para tal será necessária uma educação ambiental contínua, agregadora e transformadora para a sociedade (BRASIL, 1999).

A educação ambiental é um instrumento, ferramenta ou meio pelo qual o ser humano encontrou para sensibilizar a sociedade quanto à necessidade de se preservar e/ou conservar os recursos naturais, todo tipo de meio ambiente, as culturas, políticas e meios sociais, para as geraçóes atuais e futuras, fazendo isto por meio da mudança de atitudes, hábitos e saberes mais sustentáveis, visando uma melhor qualidade de vida para todos os seres vivos (BRASIL, 1999; REIGOTA, 2010; LIMA e COSTA, 2016). Necessita-se aplicar a educaçáo ambiental de forma crítica, contínua e dinâmica, para se conseguir atingir e sensibilizar o máximo de pessoas possíveis para elas compreenderem a importância e a necessidade de se conservar o meio ambiente natural, a sociedade e a economia, para si e para as geraçóes futuras (LIMA, 2009; REIGOTA, 2010). Transformando-as de tal maneira que elas mudem as suas atitudes e rotina pelo motivo de compreender e desejar isso e não porque se sentem obrigadas a tal.

Desta forma, o presente trabalho trata-se do resultado de um estudo de caso realizado na Pousada Sossego da Pampulha, localizada na regiáo da Pampulha, em Belo Horizonte, o qual buscou aplicar os conceitos de educação ambiental e o gerenciamento de resíduos sólidos no estabelecimento, de maneira que sensibilizasse todos os funcionários da pousada quanto à importância de ser e agir de forma sustentável, buscando promover a conservação do ambiente e dos recursos naturais em prol do bem estar dos seres humanos e da natureza.

\section{OBJETIVO}

O presente trabalho teve como foco principal identificar e avaliar o gerenciamento de resíduos sólidos e o processo da educação ambiental presentes em uma pousada situada em uma região turística e ao lado do Conjunto Moderno da Pampulha, o qual é Patrimônio Cultural da Humanidade, no município de Belo Horizonte/ MG, a região da Pampulha. E por meio de conceitos da educação ambiental, buscou sensibilizar os funcionários do estabelecimento quanto à necessidade de se preocupar e aplicar a sustentabilidade no estabelecimento e no ambiente externo a ele, a fim de que eles mesmos possam ser agentes sustentáveis e multiplicadores. 


\section{REFERENCIAL TEÓRICO}

\section{I. Sustentabilidade no Setor Hoteleiro}

A sustentabilidade pode e deve ser aplicada em todo tipo de serviço, incluindo no setor hoteleiro, o qual necessita se adequar a todas as exigências por parte do governo e da população, incluindo o que diz respeito às questôes sociais e ambientais, as quais estão crescentes e fortes atualmente (MINISTÉRIO DO TURISMO, 2016).

Há diversas medidas para boas práticas sustentáveis no setor hoteleiro. A organização mundial do turismo OMT, por exemplo, decretou 2017 como o ano internacional do turismo sustentável, com o objetivo principal de apoiar mudanças nas políticas, práticas de negócios e comportamento do consumidor no sentido de um setor do turismo mais sustentável do que pode contribuir para o desenvolvimento.

No Brasil, a Associação Brasileira de normas técnicas - ABNT em parceria o Ministério do turismo, criaram a norma número 15.401 (ABNT, 2006) sobre o sistema de gestáo da sustentabilidade nos meios de hospedagem, o qual orienta que a gestão de resíduos sólidos em qualquer meio de hospedagem, deve aderir a práticas como: "aquisição preferencialmente de produtos em embalagens para grandes quantidades; evitar o uso de descartáveis; descarte correto e coleta seletiva; e reutilização dos orgânicos”. Tal norma destina-se tanto aos meios de hospedagem que caminham em direção à certificação ambiental quanto àqueles que desejam aprimorar as práticas do turismo sustentável (PERUCHIN, 2015).

Segundo De Alencar e Rossetto (2014) a adesão e a implantação de práticas sustentáveis em hotéis e pousadas se devem primeiramente à conscientizaçáo prévia dos proprietários, com foco no mercado, na sustentabilidade e gestão. De maneira geral, os meios de hospedagem que realizam uma boa divulgaçáo de açóes socioambientais praticadas e adotadas, recebem um retorno favorável no que diz respeito à boa imagem da empresa.

Prado et al. (2015) realizaram um levantamento de práticas sustentáveis realizadas nos meios de hospedagem em Balneário de Camboriú (RS) e concluíram que de quatro hotéis pesquisados, apenas dois adotam algumas práticas sustentáveis, incluindo a utilização de produtos reciclados e a separaçáo do lixo e resíduos sólidos. E um dos dois hotéis que realizam práticas sustentáveis teve mudanças positivas e ainda redução de custos.

Enfim, ser sustentável é utilizar de todos os recursos naturais e artificiais, de maneira responsável, viável e justa tanto no âmbito socioambiental quanto econômico. O custo benefício de práticas sustentáveis, como a separaçáo de resíduos sólidos para posterior reciclagem, para o setor hoteleiro além de viável, pode ser lucrativo (SINGH et al., 2014).

\subsection{Resíduos Sólidos}

Segundo o artigo 3º inciso XVI da lei Nacional de Resíduos Sólidos, o PNRS (Lei no 12.305/10), resíduo sólido é:

"Material, substância, objeto ou bem descartado resultante de atividades humanas em sociedade, a cuja destinação final se procede, se propóe proceder ou se está obrigado a proceder, nos estados sólido ou semissólido, bem como gases contidos em recipientes e líquidos cujas particularidades tornem inviável o seu lançamento na rede pública de esgotos ou em corpos d'água, ou exijam para isso soluçóes técnicas ou economicamente inviáveis em face da melhor tecnologia disponível" (BRASIL, 2010).

A lei 12.305 ainda informa que rejeitos, são "resíduos sólidos que não podem ser reaproveitados ou reciclados" e que a reciclagem é o "processo de transformação de resíduos sólidos em novos produtos". Por meio destes conceitos, pode-se inferir que o lixo não é sinônimo de resíduos sólidos, sendo mais bem definido como sendo qualquer material ou produto que não tem mais utilidade para um determinado ser humano. Portanto, conclui-se que não são todos os tipos de materiais e alimentos que descartamos que são de fato lixos. E o que pode ser lixo para uma pessoa, para a outra é alguma utilidade. Contudo, infelizmente na nossa sociedade e em nossa cultura, a maioria dos cidadáos trata o lixo como algo que não se presta mais à utilidade original e ainda rompem o ciclo de vida de um material ou produto que poderia ter retornado ao mercado (QUERINO e PEREIRA, 2016).

Assim como todo empreendimento, os hotéis e pousadas consomem e geram resíduos, os quais, em sua maioria, se enquadram como de origem "domiciliar", segundo a Lei 12.305 de 2010. Muitas leis e normas ambientais regulamentadas fornecem à sociedade, o direito e dever de cobrar destes estabelecimentos o respeito à natureza e aos seres humanos.

Segundo os autores Corrêa et al (2014) e Querino e Pereira (2016) os tipos de "lixos" mais comuns, 
gerados nos meios de hospedagem são: resíduos orgânicos, secos (papel, plástico, vidro e metal), resíduos químicos (exemplo: produtos de limpeza) e resíduos tóxicos (pilhas).

Uma das formas de se sensibilizar a sociedade, empresários e governo quanto a esta questão, é por meio da educação ambiental. A qual também está prevista na Lei 12.305/2010 e na sua lei específica, a Lei 9.795/1999, sendo um processo e um meio que busca conscientizar e promover o desenvolvimento sustentável e a conservação em todo o meio ambiente, respeitando os limites da natureza e pensando nas geraçóes futuras.

Todo e qualquer estabelecimento deve fazer um levantamento de todos os aspectos e impactos ambientais que o seu empreendimento apresenta e gera, assim como preconiza a Lei Nacional do Meio Ambiente de número 6.938 (BRASIL, 1981).

\subsection{Gerenciamento de Resíduos Sólidos no setor hoteleiro}

O manejo inadequado de resíduos sólidos pode causar inúmeros impactos ambientais negativos (COSTA, 2013), a saber: degradação e contaminação do solo; poluição da água; proliferação de vetores; potencialização dos efeitos das enchentes; entre outros.

Logo, necessita-se de políticas adequadas para garantir a destinação correta dos resíduos sólidos. Os principais requisitos para um bom gerenciamento dos resíduos em um empreendimento, como no setor hoteleiro, são: acondicionar e armazená-los adequadamente; manter um programa interno de treinamento aos funcionários no estabelecimento, utilizando a educação ambiental como formação continuada; armazenar e destinar corretamente os resíduos sólidos contaminantes; e dispor de critérios específicos para a correta destinação desses materiais (PERUCHIN, 2015). No que concerne o treinamento ambiental, Dias-Angelo et al. (2014) esclareceram que se faz necessário treinar todos os funcionários de hotéis para se ter um bom andamento da gestão ambiental nos estabelecimentos, sendo que isto deve ser feito por meio de análises informais de todos os processos internos.

Peruchin (2015) analisou o gerenciamento de resíduos sólidos em um empreendimento hoteleiro em Pelotas/ RS e conclui que o estabelecimento não apresenta um gerenciamento de resíduos sólidos e a função de gerir o lixo era incumbida aos funcionários da limpeza e manutenção, sem ao menos os mesmos receberem capacitação para tal, mesmo que todos os funcionários tenham apresentado uma consciência ambiental relevante. Um fato interessante foi que a autora constatou que alguns funcionários realizavam a separação de resíduos sólidos mais em suas residências do que no ambiente de trabalho, devido à falta de infraestrutura no local. Ainda nesta pesquisa, constatou-se que o setor que mais gera resíduo é o da cozinha, sendo os orgânicos o tipo de resíduo gerado em abundância.

Resultados semelhantes foram percebidos por Silva et al. (2013). Neste trabalho, eles buscaram analisar as variáveis de resíduos sólidos e a questão da educação ambiental por parte dos funcionários de 12 hotéis em Boa $\mathrm{Vista/RR}$, a fim averiguar as açóes e estratégias de sustentabilidade e gestão ambiental destes meios de hospedagem. O resultado deste trabalho apontou que, no geral, os hotéis analisados estão muito distantes da sustentabilidade e tampouco do bom gerenciamento de resíduos sólidos nos estabelecimentos, mesmo havendo cooperativas de coleta seletiva e aterros no município. Além disto, apenas um hotel possui um tipo de certificação ISO 9.000 e constatou-se que um dos maiores empecilhos para se aplicar a sustentabilidade por parte do estabelecimento é a falta de educação formal dos hóspedes e funcionários, sobre essa temática. Vale ressaltar que na presente pesquisa foi avaliado que um dos fatores que pode influenciar para os 12 hotéis não realizarem a destinação adequada dos resíduos sólidos é a não promoçáo da coleta seletiva por parte da prefeitura do município.

O despreparo e o descaso às questóes ambientais no setor hoteleiro, também foram observados no trabalho de Lamas (2015a), em que diagnosticaram que a gestão de resíduos sólidos e a aplicação adequada da educação ambiental ainda não são praticadas, de forma completa e eficaz, pelos hotéis analisados no Rio de Janeiro/RJ. Sendo observada certa ausência de políticas e gestão ambiental nestes empreendimentos, mesmo havendo incentivos e motivaçôes para as boas práticas pelas questôes ambientais por parte da Organização mundial do turismo e pelos hóspedes ecologicamente corretos. Por outro lado, aqueles estabelecimentos que praticam a gestão de resíduos ou outras ações ambientais, adquirem vantagens, incluindo a redução de gastos devido a um bom e eficaz gerenciamento dos resíduos.

Otoma et al. (2013) realizaram um levantamento dos resíduos gerados em alguns setores de serviços na cidade de Da Nang no Vietnã, como hotéis, restaurantes e supermercados e diagnosticaram que os meios de hospedagem de Da Nang (uma cidade), foram os segundos maiores geradores de resíduos sólidos. Os pesquisadores ainda analisaram os tipos de resíduos sólidos gerados nestes estabelecimentos e nos hotéis a quantidade maior de resíduos foi para os plásticos e os orgânicos.

Enfim, implantar o gerenciamento de resíduos sólidos apresenta mais benefícios a malefícios, incluindo nos meios de hospedagem. Sendo os principais benefícios: poder contribuir para a geração de lucros ou redução de custos no estabelecimento, por meio da venda de recicláveis; a redução dos impactos negativos à natureza; geração 
de um diferencial competitivo no mercado, frente aos concorrentes; melhoria nas condiçóes sanitárias; melhoria na organização e liberação de espaço no estabelecimento; e aumento do bem-estar no ambiente profissional (LAMAS, 2015b; LIMA e COSTA, 2016).

\subsection{Educação Ambiental e Percepção Ambiental}

Educação Ambiental (EA) é uma dimensão essencial da educação ou meio pelo qual o ser humano encontrou para sensibilizar a sociedade quanto à necessidade de se preservar e conservar os recursos naturais em todo tipo de meio ambiente (natural e artificial) para as geraçóes atuais e futuras. Fazendo isso por meio de enfoques interdisciplinares somados a uma participação ativa e responsável do indivíduo e da coletividade, buscando promover as mudanças de atitudes, hábitos e saberes mais sustentáveis, visando uma melhor qualidade de vida para todos os seres vivos (BRASIL, 1999; DIAS, et. al, 2016).

A educação ambiental é uma vertente da educação que está prevista em lei - Lei Nacional 9.795/1999 - e de acordo com a lei, a mesma deveria ser obrigatória em todas as formas de ensino seja na educação formal, não formal e informal. Pensando na sua capacidade enquanto multidisciplinar, interdisciplinar e transdisciplinar, a EA deve ser aplicada e disseminada por todas as disciplinas e em todas as áreas de conhecimento e a todas as pessoas de diferentes idades e níveis sociais.

Pode-se dizer que a educação ambiental, quando transformadora, propóe incentivar a formação do cidadão crítico, reflexivo e ator principal de seus atos, os quais intervirão em seu meio, por intermédio de um processo de humanização social (SANTOS e LEAL, 2016). Além de levar o indivíduo e a coletividade e a construir valores na sociedade, além do ambiente escolar (SANTOS e LEAL, 2016). Sendo, portanto uma educaçáo voltada para a cidadania.

De acordo com a lei nacional da educação ambiental (Lei 9.795/99) é objetivo fundamental que todos os brasileiros possam ter um "desenvolvimento de uma compreensão integrada acerca do meio ambiente natural, artificial e cultural e suas relaçóes ecológicas, políticas, sociais, econômicas, éticas, científicas, tecnológicas e culturais" e ainda a educação ambiental deve ser contínua e permanente, promovendo uma compreensão autônoma e criativa quanto aos problemas socioambientais e as soluçôes para os mesmos, buscando intervir positivamente na percepção ambiental de todos (DIAS, et. al, 2016).

A percepção ambiental pode ser definida como uma interação do indivíduo com seu meio ambiente por intermédio dos aspectos cognitivos (CARPI, JUNIOR, S. et. al., 2014; DIAS, et. al, 2016). Não são todas as pessoas que conseguem perceber ou apreciar a natureza e a sua diversidade e tampouco se conectar a ela, ou seja, há pessoas que apresentam uma percepção ambiental maior que as demais, dependendo do meio social e cultural que estâo inseridas (CARPI, JUNIOR, S. et al., 2014).

O modo com que o indivíduo irá perceber o ambiente ao seu redor é influenciado pelos seus conhecimentos, sua carga cultural, crenças, postura ética e valores, logo, cada indivíduo apresenta uma percepção ambiental diferente. No entanto sempre há percepçóes e opinióes que se assemelham entre os indivíduos, formando-se os grupos e é por meio destes grupos que atitudes como a educação ambiental podem ser aplicadas. Quando em contato com a natureza, elementos e conhecimentos que sensibilizem a pessoa, o nível de percepçáo da mesma cresce a ponto de induzir a uma responsabilidade e conscientização ecológica (MACEDO et. al., 2017). Essa ação é proporcionada, em muitos momentos, pelo turismo sustentável.

\subsection{Educação Ambiental no Setor Hoteleiro}

Muitos hotéis no Brasil, já apresentam uma política ambiental interna ou até mesmo um sistema de gestão ambiental - ISO 14.001. São diversos os aspectos e impactos ambientais de um empreendimento hoteleiro e são variados também os indicadores ambientais a serem aplicados neste setor, mesmo muitas pessoas não enxergando os hotéis e pousadas como empreendimentos muito degradadores do meio ambiente (CORRÊA et al, 2014). Tratando-se de uma visão errônea, uma vez que todo e qualquer tipo de empreendimento apresenta seus impactos negativos e um impacto negativo perceptível no setor hoteleiro relaciona-se ao consumo e descarte excessivo dos resíduos sólidos, principalmente para os hotéis e pousadas que apresentem restaurante.

Existem algumas barreiras para a promoção e estabelecimento da sustentabilidade ambiental no setor hoteleiro, tais como o envolvimento ou não dos funcionários e clientes com as políticas ambientais, capacitação periódica para os funcionários (CORRÊA, et. al, 2014 -p.590) a insuficiente fiscalizaçáo do governo quanto às leis ambientais; e a pouca oferta de fornecedores e parceiros sustentáveis e ecologicamente corretos. Entretanto, há os benefícios, tais como o marketing verde para os estabelecimentos, o estar de acordo com as leis e normas ambientais, e a interferência positiva na economia do empreendimento (CORRÊA, et. al, 2014 - p. 593).

Silva et al. (2013) perceberam que na maioria dos hotéis estudados, de Boa Vista (RR), não há uma preocu- 
paçáo grande com o sistema de gestão ambiental, por parte dos gerentes e funcionários, o que se transfigura em uma barreira para a educação ambiental e a boa gestáo de resíduos sólidos nestes estabelecimentos. Além disto, o fato de não haver uma coleta seletiva estruturada no município, colabora para estes e outros estabelecimentos não estar de acordo com a lei 12.305/2010 dos resíduos sólidos. Os autores acreditam que o fato da cidade apresentar, em sua maioria, hotéis de pequeno e médio porte, possa justificar a falta de conhecimento e atitudes sustentáveis, uma vez que a adesão a essas atitudes é mais comum em empreendimentos de grande porte, principalmente devido a melhor condição financeira deles.

O engajamento e a conscientização ambiental de todos os envolvidos no setor hoteleiro podem ser mais eficazes caso se siga uma ordem de conscientização quanto ao gerenciamento de resíduos sólidos, passando primeiramente pelo interesse dos proprietários para assim se tornar interesse ou obrigaçóes rotineiras dos funcionários, impactando também nos hóspedes do estabelecimento (CHOU, 2014).

Nos últimos seis anos, foram emitidos no Brasil cerca de 2.230 certificaçôes da ISO 14.001, sendo pouquíssimas destas voltadas para os meios de hospedagem (Dados INMETRO, 2017). A ideia é que a consciência e preocupação ambiental aumentem no setor hoteleiro, para que assim o número de empreendimentos certificados ambientalmente, possam também crescer.

\section{MATERIAL E MÉTODOS}

O presente trabalho consiste em uma pesquisa exploratória, quantitativa e descritiva, acerca dos temas envolvendo a sustentabilidade, resíduos sólidos e a educação ambiental, aplicando esta linha de conhecimento por meio de um estudo de caso desenvolvido em uma pousada da região da Pampulha em Belo Horizonte, de porte médio (apresenta mais de 30 quartos).

A regiāo da Pampulha se encontra no município de Belo Horizonte/MG, sendo tombada no ano de 2016 como patrimônio cultural da humanidade. A Pousada Sossego da Pampulha é de fácil acesso e situa-se na referida regiáo, mais especificamente no bairro São Luiz, justificando a escolha do local para este estudo.

Como forma de diagnosticar as práticas ambientais já existentes na pousada e também avaliar o grau de instrução dos funcionários acerca da temática de sustentabilidade ambiental e resíduos sólidos, foi aplicado à proprietária do estabelecimento e a todos os funcionários (11 pessoas), questionários estruturados (com perguntas fechadas preestabelecidas e direcionadas para o tema do projeto) no início do projeto (abril de 2017) e ao final (julho de 2017), contendo o perfil dos funcionários e 7 perguntas sobre o tema, similares em ambos questionários, a fim de avaliar o grau de percepção ambiental dos mesmos sobre a gestão de resíduos sólidos no setor hoteleiro, antes e após as propostas de sustentabilidade ambiental, desenvolvidas durante o estudo de caso. Além dos questionários, foram desenvolvidas outras atividades na pousada durante o estudo de caso, no período de maio a julho de 2017, foram elas:

- Palestra sobre Sustentabilidade ambiental, resíduos sólidos e educação ambiental;

- Palestra sobre a legislaçáo ambiental envolvendo resíduos sólidos e setor hoteleiro;

- Palestra sobre Mercado verde e turismo sustentável;

- Criação de um grupo no Whatsapp com os funcionários da pousada, para esclarecimentos e dúvidas no decorrer do projeto;

- Proposta de café da manhã sustentável, roteiro turístico ecológico e divulgaçóes sobre temas e programaçóes ambientais nas mídias sociais, na semana em comemoração ao dia mundial do meio ambiente (5 de junho);

- Pesagem e classificação dos resíduos sólidos da Pousada Sossego da Pampulha;

- Acompanhamento de todos os setores do estabelecimento;

- Realizar um levantamento de todos os resíduos sólidos adquiridos e utilizados na pousada;

- Proposta de criação de adesivos de resíduos sólidos recicláveis e não recicláveis para todas as lixeiras do estabelecimento.

Na presente pesquisa, os dados foram coletados por meio de: observação durante as visitas técnicas ao estabelecimento; a aplicação de questionário estruturado; adesão dos internautas às mídias sociais da pousada (instagram, facebook e blog); comunicaçáo entre a pesquisadora e os funcionários da pousada; depoimento de alguns funcionários sobre as atividades realizadas no estabelecimento; e outros dados e informaçôes cedidos pela administração da Pousada Sossego da Pampulha.

É importante comentar, que durante o estudo de caso, alguns funcionários e os proprietários entraram no período de férias e um deles deixou de trabalhar no estabelecimento. Ou seja, foram poucos funcionários que participaram de todos os processos e ações ambientalmente sustentáveis na pousada, do início ao fim.

Os resultados obtidos foram tabulados utilizando o Microsoft Excel 2013 e posteriormente apresentados 
Figura 1 - Mapa de Belo Horizonte/MG mostrando a regiāo da Pampulha, o local e a foto da localizaçáo e identificaçáo da Pousada Sossego da Pampulha

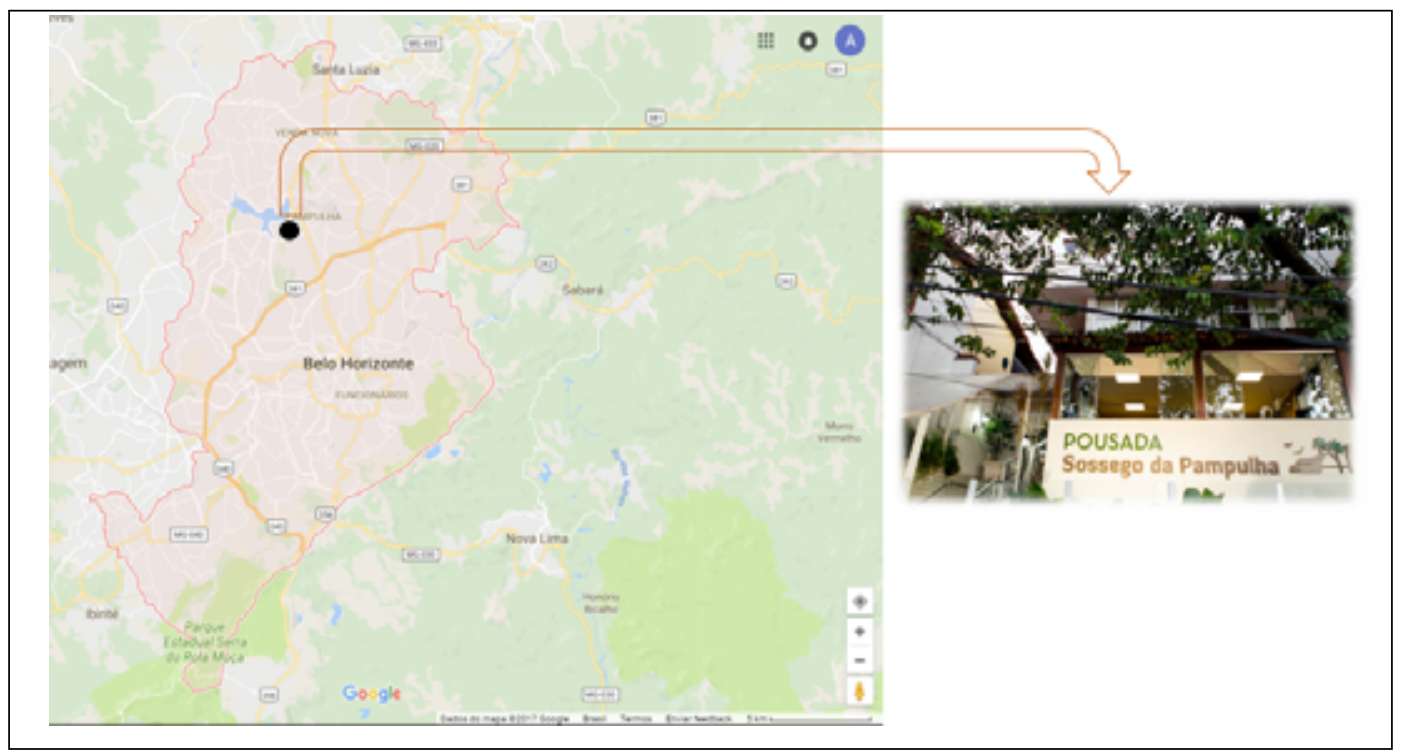

Fonte: Google maps (2017) e site da Pousada Sossego da Pampulha (2017)

em formas de gráficos, quadros e tabelas, por meio de dados qualitativos e quantitativos, utilizando-se da estatística descritiva para os dados qualitativos e da estatística básica (cálculos de média e porcentagem) para os dados quantitativos.

\section{RESULTADOS E DISCUSSÃO}

A gestão de resíduos sólidos foi o principal indicador ambiental, avaliado na Pousada Sossego da Pampulha. A pousada, antes do presente estudo de caso, já realizava algumas ações em prol do meio ambiente (Projeto Mude o mundo), sendo que a adesão às estas práticas se deveu ao interesse dos proprietários do estabelecimento, fato também observado no estudo de caso de De Alencar e Rossetto (2014). No trabalho de Prado et al. (2015), também foram estudados meios de hospedagem que já realizavam açôes ambientais antes da aplicaçáo do estudo pelos pesquisadores. Seguem abaixo exemplos de atitudes ambientalmente sustentáveis exercidas pela Pousada Sossego da Pampulha, anteriormente ao estudo de caso:

- Coleta seletiva para papel, plástico, metal e vidro;

- Uso de lâmpadas fluorescentes compactas de baixo consumo e destinação à reciclagem quando queimadas.

- Campanha para o uso consciente de roupa de cama e toalhas, pelos hóspedes;

- Uso de uma máquina ecológica de lavar louças

- Aparelhos eletrônicos de baixo consumo de energia e sensores de presença.

- Incentivo para que os hóspedes utilizem os mesmos lençóis e toalhas por mais de um dia em sua permanência.

- Jardins com plantas nativas da região, manutenção com uso reduzido de herbicidas, pesticidas e outros compostos químicos.

- Plano de manutenção preventiva para garantir o funcionamento eficiente dos equipamentos que dependem de água e energia e treinamento periódico para atualizaçáo dos funcionários.

A direção da pousada informou que com a adoção às práticas ambientais, principalmente em relação à economia de energia, ajudou na redução de custos para o estabelecimento. Como também observado no trabalho de Prado et al. (2015). Em se tratando da lavanderia, a pousada optou por terceirar este serviço, portanto, neste trabalho não foram avaliados resíduos ou atitudes sustentáveis deste setor.

Apesar de a pousada ter implantado, anteriormente, algumas ideias e práticas ecologicamente corretas, náo havia ocorrido uma educação ambiental contínua a ponto de sensibilizar e contextualizar os funcionários quanto à importância e necessidade de se manter e aplicar diária e corretamente tais ações. 
A falta de interesse e preocupaçáo com a boa gestáo ambiental do estabelecimento, por parte de alguns funcionários da pousada, percebida no trabalho de Silva et al. (2013), também foi diagnosticada no presente estudo de caso. No entanto, a hipótese encontrada no estudo de Silva et. al. (2013), justificando que o baixo interesse e adesão às práticas ambientalmente sustentáveis ocorreram em maior quantidade em hotéis de pequeno e médio porte, foi refutada com este trabalho. Uma vez que a Pousada Sossego da Pampulha configura um estabelecimento de médio porte e que já apresentada ideias e açóes ambientais antes da aplicação deste estudo de caso. A justificativa mais plausível é que os proprietários da pousada já apresentavam um interesse e preocupação ambiental significativo, sendo o acesso ao conhecimento e a percepçáo ambiental, fatores que provavelmente interfiram mais nos posicionamentos e nas políticas ambientais de um determinado empreendimento, do que necessariamente o porte do estabelecimento.

É importante comentar, que durante o estudo de caso, alguns funcionários e os proprietários entraram no período de férias e um deles deixou de trabalhar no estabelecimento. Ou seja, foram poucos funcionários que participaram de todos os processos e ações ambientalmente sustentáveis na pousada, do início ao fim.

\section{I. Atividades de Educação Ambiental aplicadas na pousada}

Seguindo a linha de raciocínio de CHOU (2014), o processo de comunicação para a conscientizaçáo sobre o gerenciamento de resíduos sólidos na Pousada Sossego da Pampulha, iniciou pela diretoria para depois ser aplicado aos funcionários e indiretamente aos hóspedes.

A aplicação do questionário inicial de percepção ambiental foi utilizada para se avaliar o grau de percepçáo ambiental dos funcionários da pousada, acerca de assuntos ambientais envolvendo sustentabilidade e resíduos sólidos, com o intuito de descobrir os pontos mais importantes sobre educação ambiental e resíduos sólidos a se trabalhar com os funcionários da pousada. E o questionário final foi aplicado a fim de verificar se houve aprimoramento e assimilaçáo dos saberes trocados eventualmente.

Em se tratando da formação e troca de experiências e saberes, foram ministradas três palestras (Quadros 1, 2 e 3 e Figura 1), descritas nos quadros a seguir.

Quadro 1 - Palestra 1, sobre resíduos sólidos e educaçáo ambiental como ferramenta para a sustentabilidade

\begin{tabular}{|c|}
\hline Conteúdo programático \\
\hline${ }^{*}$ conceitos sobre resíduos sólidos, lixo, educação ambiental e sustentabilidade \\
\hline *desenvolvimento sustentável \\
\hline *descarte do lixo \\
\hline${ }^{*}$ classificação dos resíduos sólidos e coleta seletiva \\
\hline${ }^{*}$ Recicláveis e não recicláveis \\
\hline${ }^{*}$ Soluções e alternativas para o problema do lixo no Brasil e na pousada \\
\hline
\end{tabular}

Quadro 2 - Palestra 2 sobre as leis de resíduos sólidos no Brasil e a sustentabilidade no setor hoteleiro

Conteúdo programático

*Lei, normas e decretos envolvendo resíduos sólidos no âmbito federal, estadual, municipal e local

*ênfase na lei 12.305/2010 - Política dos resíduos sólidos

*Plano municipal de gerenciamento integrado dos resíduos sólidos

*ISO 15.401/2006 - sustentabilidade no setor hoteleiro

*ABIH - Associação Brasileira da Indústria de Hotéis 


\begin{tabular}{|l|}
\hline \multicolumn{1}{|c|}{ Conteúdo programático } \\
\hline *Conceitos envolvendo mercado verde, selo verde, certificação ambiental e turismo sustentável \\
\hline *principais rótulos ambientais \\
\hline *princípios do turismo sustentável \\
\hline
\end{tabular}

Figura 2 - Palestras e dinâmica realizadas na pousada entre maio a julho de 2017. (Figura 1.a. Palestra 1; Figura 1.b. Palestra 2; Figura 1.c. dinâmica após palestra 2; Figura 1.d. Palestra 3 (Ordem das fotos: da direita para a esquerda começando da parte superior até a inferior)

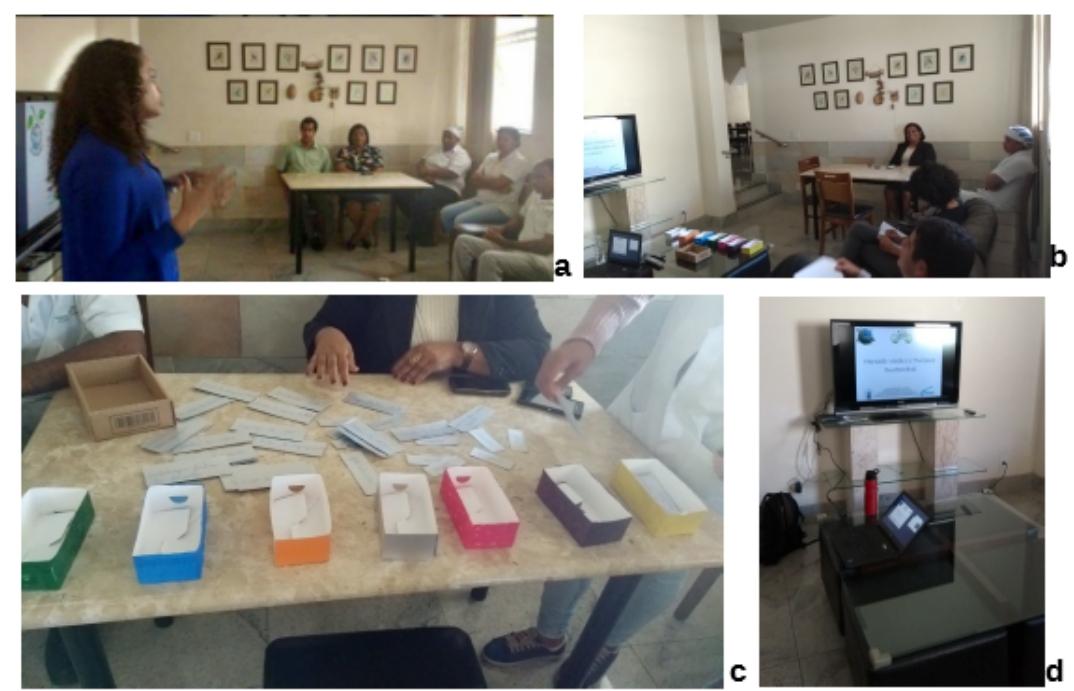

Fonte: Arquivo pessoal, 2017

A palestra inicial - Palestra 1 (Figura 1.a e quadro 1) foi divulgada também para a comunidade do bairro onde se localiza a pousada, no entanto, não houve o comparecimento de outras pessoas além dos funcionários. Esta palestra foi realizada em quatro momentos (aplicada a todos os 12 funcionários e proprietária do estabelecimento), considerando a rotina e turnos de trabalho de todos os funcionários. Em se tratando das palestras 2 e 3 (Figuras 1.b e quadro 2 e figura 1.c e quadro 3, respectivamente), as mesmas foram apresentadas para poucos funcionários, devido à problema de logística de trabalho, e para os demais funcionários que não participaram presencialmente, foram disponibilizadas as apresentaçōes das mesmas em documento power point, sendo também preparado um documento contendo o resumo dos assuntos abordados nestas apresentaçóes e posteriormente este documento foi entregue àqueles funcionários que não puderam participar das últimas palestras.

As palestras foram fundamentais para contextualizar, informar e sensibilizar todos os participantes quanto à necessidade e importância da sustentabilidade e o gerenciamento de resíduos sólidos no setor hoteleiro. Na primeira palestra foi constatado que a maioria dos funcionários desconhecia termos, contextos, causas e consequências relacionadas aos resíduos sólidos. Além disto, foi percebido certo desinteresse e desconhecimento sobre o assunto por parte de algumas pessoas, mesmo tendo ocorrido perguntas e discussões durante a apresentação. Como tentativa de mudar isto, nas outras palestras a autora buscou ser mais didática e objetiva em suas proposiçóes e também mais questionadora, como forma de fazê-los argumentar e ser mais críticos em relação aos temas abordados, fato que vai de encontro ao proposto apresentado por Santos e Leal, (2016), sendo de extrema importância quando se deseja utilizar a educação ambiental crítica.

Após a palestra 2 (quadro 2), foi realizada uma dinâmica com os funcionários da pousada presentes no dia. A dinâmica se baseou nos conceitos e características da coleta seletiva, mais profundamente na identificação das lixeiras da coleta seletiva (em consonância à resolução CONAMA número 275). Na dinâmica proposta, foram disponibilizados aos funcionários, vários itens correspondendo a tipos variados de resíduos sólidos (escritos em papel de caixas de leite reaproveitadas) e também todas as lixeiras existentes da coleta seletiva (representadas por caixas 
de papel pequenas e coloridas com papeis e plásticos reaproveitados (vide figura 1.c). Os funcionários tiveram um tempo para descartar corretamente todos os resíduos sólidos apresentados nas respectivas lixeiras da coleta seletiva. Foi um momento de aprendizado lúdico e de interação entre todos os participantes, inclusive de ajuda mútua entre eles, atitude que é importante para o processo de aprendizagem coletiva. O resultado foi positivo, ocorrendo $91,7 \%$ de acertos e apenas $8,3 \%$ de erros.

Seguindo as teorias apresentadas nos documentos de Santos e Leal, (2016), Carpi-Junior, S. et. al. (2014) e Dias, et. al. (2016), buscou-se não apenas informar e caracterizar as ferramentas da coleta seletiva, mas sim contextualizar e colocar cada ser humano, incluindo os funcionários, como os principais responsáveis pelo acúmulo de lixo descartado diariamente e também os responsáveis pelas futuras mudanças positivas na natureza. Desta forma, pode-se inferir que ocorreu uma educaçáo ambiental crítica e não conservadora.

Vale frisar que a maioria dos funcionários não tinha ciência de todos os problemas causados pela má gestão de resíduos sólidos e tampouco sabiam do elevado grau de significância do papel de cada indivíduo em relação a isto. Pois a tendência são as pessoas se excluírem das responsabilidades e papeis socioambientais, esquecendo que cuidar do meio ambiente é também um dever de todo cidadão. Em contrapartida, houve exemplos de funcionários que foram participativos, questionadores e interessados durante todas as atividades propostas, inclusive com relatos de experiências vividas no que diz respeito à temática, tendo também iniciado a aplicação dos conhecimentos aprendidos no dia a dia.

Ao longo do estudo de caso, foram informados e contextualizados vários conceitos sobre as temáticas de sustentabilidade, educação ambiental e resíduos sólidos. Dentre elas, desmistificou a ideia de que reciclar e reaproveitar são sinônimos e que a sustentabilidade não se aplica apenas às questóes ambientais, mas também no âmbito econômico, político, cultural e social.

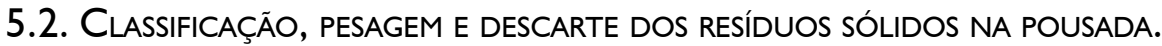

A Pousada Sossego da Pampulha trata-se de um estabelecimento prestador de serviço e de acordo com a lei 12.305/2010 todos os seus resíduos sólidos gerados são enquadrados como resíduos sólidos domiciliares e, portanto, podem e devem ser recolhidos periodicamente pelo processo de coleta domiciliar do lixo, realizado semanalmente pela Superintendência de limpeza urbana - SLU de Belo Horizonte, nas segundas, quartas e sextas feiras. Quanto à coleta seletiva, esta é efetivada todas as quintas feiras, por sistema de coleta porta a porta.

Como forma de conhecer e avaliar os resíduos sólidos adquiridos, utilizados e descartados na pousada, no período do estudo de caso do projeto pela autora, foram listados, classificados e pesados os resíduos sólidos gerados pelos funcionários e clientes. Baseando-se na norma da ABNT 10.004 de 2004, os resíduos sólidos da pousada foram classificados conforme descrito no quadro 4.

Quadro 4 - Classificação dos resíduos sólidos da pousada

\begin{tabular}{|c|c|c|}
\hline \multicolumn{3}{|c|}{ Classificação e pesagem dos residuos sólidos na pousada sossego da pampulha } \\
\hline \multirow{2}{*}{ Resíduos sólidos classe I - Perigosos } & \multicolumn{2}{|c|}{$\begin{array}{l}\text { Resíduos sólidos casse II - Não perigosos (exemplos: papel, plástico, } \\
\text { metal, alimentos, tecidos) }\end{array}$} \\
\hline & $\begin{array}{l}\text { Residuos sólidos classe П A - } \\
\text { Não Inerte }\end{array}$ & $\begin{array}{l}\text { Residuos sólidos Classe I B - } \\
\text { (Inertes) }\end{array}$ \\
\hline Pilhas e baterias & \multirow{6}{*}{$\begin{array}{l}\text { basicamente todos os residuos de } \\
\text { origem domiciliar (Grupo D) }\end{array}$} & \multirow{6}{*}{$\begin{array}{l}\text { alguns residuos de construção civil } \\
\text { (ex: entulhos e pedras) }\end{array}$} \\
\hline lầmpadas fluorescentes & & \\
\hline Cloro e água sanitária & & \\
\hline Desentupidor de pia & & \\
\hline medicamentos vencidos & & \\
\hline Limpador de vidro & & \\
\hline
\end{tabular}

Fonte: Arquivo pessoal, 2017

Os resíduos sólidos listados no quadro 4, foram praticamente os mesmos resíduos citados, nos meios de hospedagem, por Corrêa et al (2014) e Querino e Pereira (2016). Como previsto pela lei nacional dos resíduos sólidos (Lei 12.305 de 2010), no processo de gerenciamento de resíduos sólidos, deve-se realizar além da classificação, a pesagem dos resíduos sólidos gerados pelo estabelecimento. Este procedimento está sintetizado no Gráfico 1. 
Gráfico 1 - Pesagem dos resíduos sólidos da pousada realizado em dois dias aleatórios

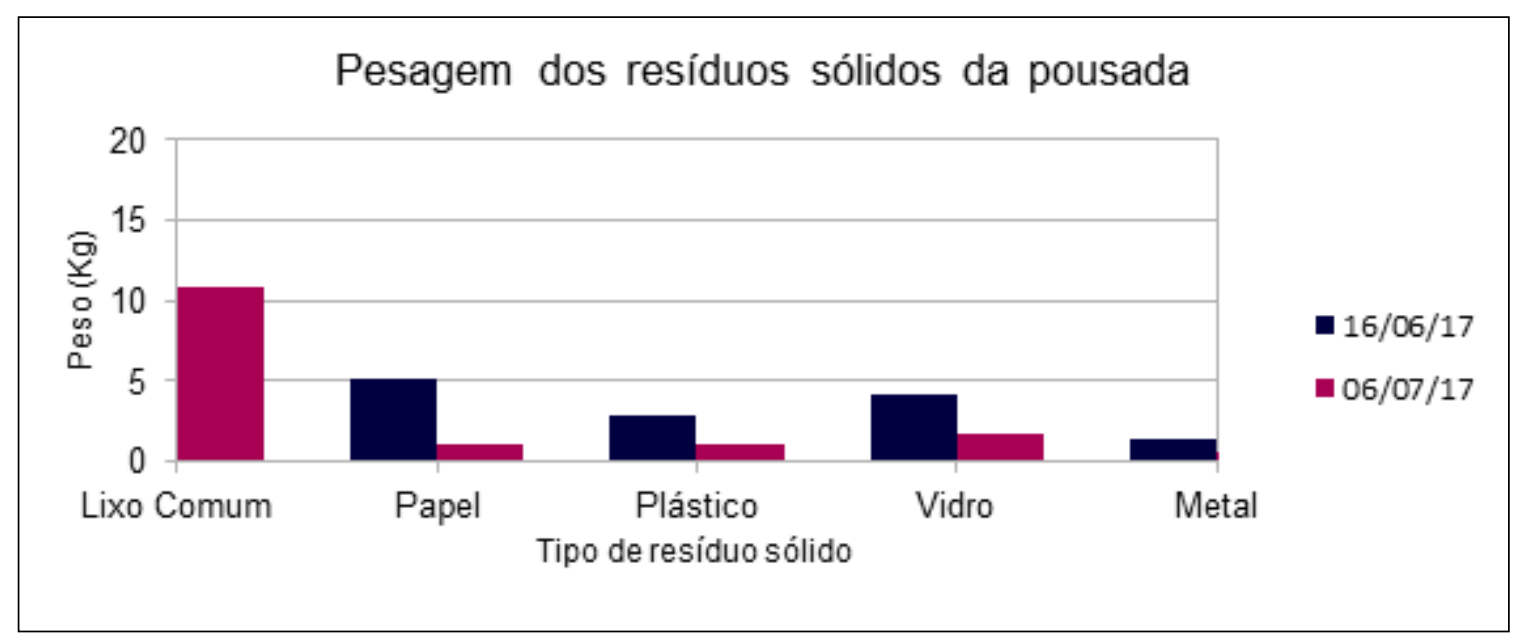

Fonte: Arquivo pessoal, 2017

O gráfico 1 apresenta a pesagem dos resíduos sólidos da pousada realizada em dois dias aleatórios, sendo a primeira pesagem realizada na segunda quinzena de junho (16/06/2017) e a segunda pesagem realizada no início de julho (06/07/2017). Na primeira pesagem a pousada se encontrava com lotação dos quartos (com 60 pessoas hospedadas), devido ao feriado nacional (Feriado de Corpus Christi no dia 15 de junho de 2017), em contrapartida, na segunda pesagem, a pousada se encontrava com um número de hóspedes padrão - 26 pessoas. Outra questão visível, é que a quantidade de resíduos descartados no lixo comum, foi superior e abundante se comparado aos resíduos sólidos descartados para a coleta seletiva. Vale comentar que durante as duas pesagens dos resíduos, foi observado que havia resíduos sólidos descartados de modo errado nas lixeiras de coleta seletiva e que muitos resíduos sólidos que poderiam ser reaproveitados ou direcionados para a reciclagem, foram descartados na lixeira de lixo comum, sendo que o lixo deveria ser composto apenas por rejeitos. Logo, percebe-se que os informativos e açóes de educação ambiental estão insuficientes na pousada, principalmente para o acesso e conhecimento dos clientes.

Ao contrário do encontrado por Otoma (2013), a maior quantidade de resíduos sólidos descartados e observados durante as pesagens, foi de lixo comum e de papéis. Realizando uma média entre as duas pesagens realizadas, obtém-se o valor de $23,5 \mathrm{kgs}$ para a produção diária de lixo no presente estabelecimento, volume este que é inferior ao volume total de resíduos descartados por dia em cada hotel analisado no trabalho de Otoma (2013).

Durante a pesagem e a classificação dos resíduos sólidos da pousada, foi percebido que ocorreram erros na separação dos materiais, como: lâmpadas fluorescentes descartadas junto com os vidros, sendo que estas lâmpadas são resíduos perigosos; papel sendo descartado junto com os plásticos e plástico descartado com metal. Também foi observado neste estudo e assim como no trabalho de Peruchin (2015) que ocorreu uma abundância, mais considerável, de geração de resíduos sólidos nos setores de limpeza e da cozinha, se comparado aos outros setores e dentre eles os orgânicos também foram os resíduos encontrados em maior quantidade. A figura 2 apresenta o local onde foi realizada a pesagem dos resíduos sólidos recicláveis.

Figura 2 - Lixeiras para coleta seletiva, localizadas na garagem da pousada

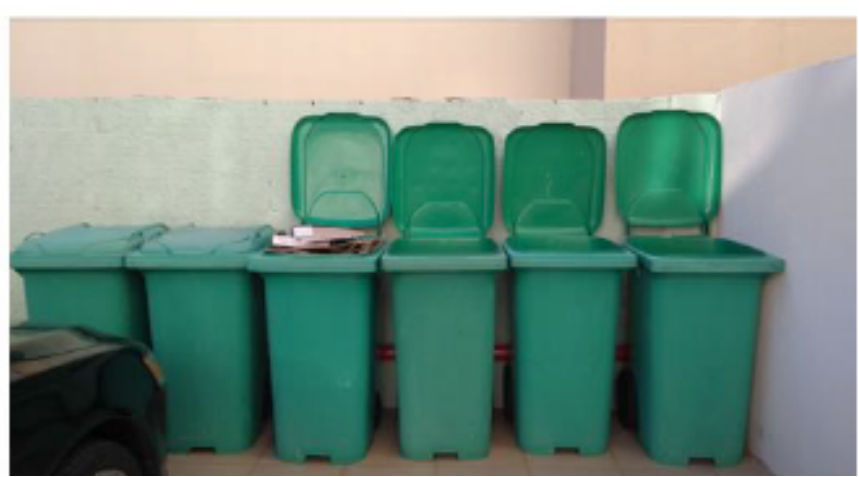

Fonte: Arquivo pessoal, 2017 


\subsection{Comemoração da semana do meio ambiente na Pousada Sossego da Pampulha}

No dia 5 de junho de 2017, comemorou-se o dia mundial do meio ambiente e nacionalmente de 4 a 10 de junho, a semana do meio ambiente. Em alusão à importância desta data, foram propostas à pousada, algumas açôes a serem desenvolvidas durante a semana em prol do meio ambiente e do bem comum. As açōes propostas na pousada para a semana do meio ambiente, foram: divulgar para os hóspedes sobre a coleta seletiva presente na pousada e incentiva-los a aderir à mesma; divulgar assuntos ambientalmente sustentáveis nas mídias sociais do estabelecimento; oferecer para os clientes um roteiro ecológico de visitação em $\mathrm{BH}$; no café da manhã, oferecer aos hóspedes um cardápio com alimentos saudáveis e reaproveitáveis (como chá com casca de fruta); e recolher o óleo de cozinha usado para posterior reciclagem. Durante esta semana, também foi criado um grupo na rede social, whatsapp, para aumentar e facilitar a comunicação entre a autora do manual e os funcionários da pousada, no que diz respeito às dúvidas, curiosidades e repasses sobre a temática de resíduos sólidos. Tal grupo se manteve até o final do trabalho.

Durante a semana do meio ambiente, ocorreram alguns empecilhos quanto às atividades propostas, como: a pousada recebeu poucos hóspedes durante a semana em questão, o que prejudicou a adesão às ideias e a maior repercussão e visibilidade das ações por parte dos clientes e funcionários; os funcionários iriam participar de um evento ambiental externo, mas o evento foi cancelado; os funcionários não aderiram à proposta de coletar o óleo de cozinha usado, em casa, para destina-los à reciclagem. Em contrapartida, as divulgaçôes sobre sustentabilidade, turismo ecológico e boas práticas do gerenciamento de resíduos sólidos, foram realizadas durante toda a semana e tiveram uma repercussão razoável. O que contribui para a boa imagem da pousada, conforme comentado por De Alencar e Rossetto (2014).

\subsection{RESULTADOS DO QUESTIONÁRIO DE PERCEPÇÃO AMBIENTAL DOS FUNCIONÁRIOS DA POUSADA}

Foi aplicado um questionário de percepção ambiental anterior e posteriormente às ações sustentáveis desenvolvidas na pousada durante o estudo de caso e após a análise comparativa entre os questionários, conclui-se que houve uma melhora da percepção ambiental por parte dos funcionários da pousada, uma vez que no segundo questionário foram percebidos mais acertos do que erros e posicionamentos mais ambientalmente corretos (vide quadro 5)

A aplicação do questionário inicial de percepção ambiental acerca de sustentabilidade e resíduos sólidos permitiu que se identificassem alguns pontos principais a se trabalhar com os funcionários da pousada, são eles: conceitos e definiçôes básicas sobre resíduos sólidos e sustentabilidade; classificação dos resíduos sólidos e referência de cores da coleta seletiva; desenvolvimento sustentável; e causas e consequências do impacto ambiental do descarte incorreto do lixo. Além de avaliar o grau de percepção ambiental dos funcionários da pousada, o qual apresentou ser bom em se tratando do saber da importância de se conservar ou preservar a natureza e da consciência que o lixo é um problema ambiental, foi avaliado também a participaçáo deles em açōes ambientalmente sustentáveis no ambiente familiar e do trabalho. Descreve-se a seguir o resultado do perfil, através do preenchimento do questionário, por cada funcionário.

Ao total foram entrevistados 12 funcionários, no primeiro questionário e 11 funcionários no último, incluindo a proprietária do estabelecimento e os funcionários do setor de administração, comercial e marketing, recepção, limpeza e cozinha. Dentre os 12 entrevistados, 5 são mulheres e 7 homens. Em relação à naturalidade dos mesmos, 6 são naturais de Belo Horizonte, um é natural de Homs na Síria e os demais são naturais de cidades do interior de Minas Gerais.

Quanto ao grau de instrução, a maioria dos funcionários - 46\% - têm ensino médio, 36\% têm no mínimo a graduação e apenas $18 \%$ têm o ensino fundamental, o que implica que o grau de instrução dos avaliados é relevante e que a maioria deles, durante o período de estudo passaram por disciplinas e pesquisas que faziam alusão à conscientização sobre os problemas ambientais, mesmo que superficialmente.

Quanto à faixa etária, a metade dos funcionários apresenta idade entre 36 a 45 anos. Fator que influencia na percepçáo ambiental, uma vez que pessoas nesta faixa etária costumam apresentar um nível de aprendizado e experiência maiores.

Tais resultados são relevantes, visto que a idade, o ambiente em que cada pessoa foi criada e o contato que ela tem com a natureza durante a graduaçáo ou escola, influenciam na percepçáo ambiental que ela terá. Em relação à segunda parte de ambos os questionários, perguntas específicas, obteve-se a relação de respostas apresentadas no quadro 5. 
Quadro 5 - Comparativo entre os questionários de Percepção Ambiental dos funcionários da Pousada

\begin{tabular}{|c|c|c|}
\hline PERGUNTAS DO QUESTIONÁRIO & $\begin{array}{l}\text { RESPOSTA DO PRIMEIRO } \\
\text { QUESTIONÁRIO }\end{array}$ & $\begin{array}{l}\text { RESPOSTA DO SEGUNDO } \\
\text { QUESTIONÁRIO }\end{array}$ \\
\hline $\begin{array}{l}\text { Conservação e o uso racional dos recursos } \\
\text { naturais pelas pessoas e empreendimentos }\end{array}$ & $\begin{array}{c}\text { Todos concordam sobre a relevância e } \\
\text { importância da conservaçáo da natureza e } \\
\text { todos seus recursos. }\end{array}$ & $\begin{array}{l}\text { Todos concordam sobre a relevância e } \\
\text { importância da conservaçáo da natureza e todos } \\
\text { seus recursos. }\end{array}$ \\
\hline $\begin{array}{l}\text { Importância das leis para resíduos sólidos e a } \\
\text { separação e destinação correta dos mesmos }\end{array}$ & $\begin{array}{c}\text { Todos julgam importante realizar a separação e } \\
\text { destinaçáo correta dos resíduos sólidos }\end{array}$ & $\begin{array}{l}\text { Todos continuam julgando ser importante realizar } \\
\text { a separação e destinação correta dos resíduos } \\
\text { sólidos }\end{array}$ \\
\hline $\begin{array}{l}\text { Importância da aplicação da educaçáo } \\
\text { ambiental e do desenvolvimento sustentável }\end{array}$ & $\begin{array}{c}\text { Todos consideram a educação ambiental } \\
\text { um instrumento importante para todas as } \\
\text { atividades }\end{array}$ & $\begin{array}{c}\text { Todos continuam considerando a educação } \\
\text { ambiental um instrumento importante para todas } \\
\text { as atividades }\end{array}$ \\
\hline $\begin{array}{l}\text { Reaproveitamento e reciclagem prévia dos } \\
\text { resíduos sólidos antes de destina-los ao aterro } \\
\text { sanitário }\end{array}$ & $\begin{array}{l}\text { Todos consideram relevante o } \\
\text { reaproveitamento e reciclagem de materiais. }\end{array}$ & $\begin{array}{c}\text { A maioria continuou julgando importante } \\
\text { reaproveitar e reciclar os resíduos. Porém, uma } \\
\text { parcela de funcionários que informou que } \\
\text { os resíduos sólidos devem ser direcionados } \\
\text { diretamente para o aterro sem haver a reciclagem } \\
\text { dos mesmos. }\end{array}$ \\
\hline $\begin{array}{l}\text { Turismo sustentável e seus benefícios para o } \\
\text { lado social, cultural, ambiental e econômico }\end{array}$ & Pergunta específica do questionário 2. & $\begin{array}{l}\text { Todos consideram que há benefícios com o } \\
\text { turismo sustentável }\end{array}$ \\
\hline Lixeiras da coleta seletiva & $\begin{array}{c}\text { De } 12 \text { questionários, apenas } 5(41,66 \%) \\
\text { funcionários sabiam as cores corretas das } \\
\text { lixeiras da coleta seletiva }\end{array}$ & $\begin{array}{l}\text { Em } 11 \text { questionários, } 8(72,7 \%) \text { funcionários } \\
\text { souberam responder corretamente as cores } \\
\text { corretas das lixeiras para coleta seletiva }\end{array}$ \\
\hline Coleta seletiva em casa & $58,3 \%$ realizava a coleta seletiva em casa & $\begin{array}{l}90,9 \% \text { passaram a separar corretamente os } \\
\text { resíduos em casa }\end{array}$ \\
\hline Coleta seletiva no trabalho & $\begin{array}{c}\text { Apenas } 25 \% \text { separa os resíduos sólidos } \\
\text { corretamente no trabalho }\end{array}$ & $\begin{array}{l}81,8 \% \text { separam corretamente os resíduos sólidos } \\
\text { no trabalho }\end{array}$ \\
\hline Práticas sustentáveis na pousada & $\begin{array}{l}\text { 91,7\% julgaram importante práticas ações } \\
\text { ambientalmente sustentáveis nos meios de } \\
\text { hospedagem }\end{array}$ & $\begin{array}{l}100 \% \text { dos funcionários julgam ser importante } \\
\text { aplicar e manter práticas sustentáveis na pousada }\end{array}$ \\
\hline
\end{tabular}

Fonte: Arquivo pessoal, 2017

A respeito do quadro 5, pode-se perceber que é unânime que todos os funcionários julgam importantes as açôes em defesa da conservação e preservaçáo do meio ambiente e social. No entanto, foi observado, via questionário e por meio de observaçáo e conversa com todos os participantes, que apesar de todos terem ciência da importância de se tratar bem as questóes ambientais, a maioria não realiza atitudes no dia a dia, em casa e no trabalho, que colabore para a conservação e preservação da natureza.

Apesar deste fato, foi muito perceptível que ocorreu um aprimoramento dos conhecimentos dos funcionários em relação à conservação dos recursos naturais e em específico, sobre a importância do gerenciamento dos resíduos sólidos. As informações novas recebidas durante as palestras e visitas técnicas do estudo de caso, foram essenciais para a sensibilização dos mesmos quanto à necessidade do papel deles enquanto indivíduo e coletivo para a natureza e a sociedade. Foi constatado que após as açóes realizadas na pousada, alguns funcionários que antes não realizam corretamente a coleta seletiva, disseram que passaram a aderir à mesma, em casa e no trabalho.

Pode-se inferir com esses resultados, que de fato houve uma melhora de percepção ambiental, porém com maior propriedade com aqueles funcionários que participaram de todas as atividades ambientais propostas. De qualquer forma, este aumento da percepção ambiental ainda não foi o suficiente para todos os funcionários, ainda há muito que se trabalhar com os mesmos. Em relação aos funcionários (apenas dois) do período noturno, não foram diagnosticadas mudanças relevantes na percepção ambiental, fato que pode ser justificado por estes funcionários não terem participado de todas as atividades, devido à incompatibilidade de horários.

Enfim, por meio dos questionários e de alguns depoimentos coletados via whatsapp e e-mail, percebe-se que todos os funcionários entendem e sabem que há vários problemas ambientais envolvendo os resíduos sólidos, no entanto raros percebem e entendem que fazem parte de todos os processos e causas dos problemas envolvendo os resíduos e tendem a se sensibilizar e mudar de atitudes e abandonar maus hábitos. Como o processo de educação ambiental é lento, é necessário que mais açôes ambientalmente corretas e formaçôes continuadas 
sejam aplicadas a todos da pousada, de forma que eles possam se sensibilizar e aderir inteiramente às causas e açôes ambientais, principalmente aquelas envolvendo a gestão correta e adequada dos resíduos sólidos.

Em suma, o questionário final de percepção ambiental, aplicado após as ações e atividades de educação ambiental e gerenciamento de resíduos sólidos, apresentou melhoras no conhecimento dos funcionários, principalmente acerca da diferenciação correta entre as lixeiras principais de coleta seletiva. Evidenciou também um interesse razoável dos funcionários em querer aderir à coleta seletiva no seu lar, além do ambiente de trabalho, o qual já apresenta a ação de destinaçáo correta e coleta seletiva.

\subsection{Proposta de boas práticas de gerenciamento de resíduos sólidos na Pousada Sossego da PAMPULHA}

Somadas as açóes e atividades executadas com as boas perspectivas do estabelecimento, podem-se sugerir as mesmas ou mais ações e atividades a serem criadas ou mantidas na Pousada Sossego da Pampulha, contando com o engajamento e envolvimento de todos os funcionários e os hóspedes do local. Como forma de consolidar todos os aprendizados e saberes compartilhados e de procurar manter um bom gerenciamento de resíduos sólidos na pousada, foram elaborados um manual e uma cartilha de boas práticas para o gerenciamento de resíduos sólidos na pousada, especificando açóes ambientalmente sustentáveis para cada setor do estabelecimento, incluindo uma orientação para melhores parceiros e fornecedores ambientalmente corretos em Belo Horizonte e região.

Em se tratando dos resíduos sólidos e produtos adquiridos nos meios de hospedagem, um ponto que foi citado e reforçado no manual criado, foi sobre a importância de realizar a troca de certos insumos por outros mais ecologicamente corretos. Vale comentar que a administração da pousada informou que após as açóes aplicadas na pousada, os funcionários passaram a utilizar garrafinhas ou copos de vidro para beber líquidos ao invés de utilizar copos descartáveis durante a jornada de trabalho. Os informativos (referente à cartilha criada para a pousada) afixados na sala dos funcionários, provavelmente ajudaram nesta conscientização.

O presente estudo corroborou um fato citado por Silva e colaboradores (2013), em que a presença de uma educação ambiental contínua e eficiente, é crucial para o envolvimento dos funcionários e hóspedes de um meio de hospedagem.

De forma geral, os funcionários da pousada, assim como observado também nos participantes do estudo de Lamas (2015a), demonstraram no início do estudo, muito despreparo e pouca pró-atividade no que diz respeito ao cumprimento dos processos de gerenciamento de resíduos sólidos.

Os requisitos citados por Peruchin (2015) foram cumpridos no presente estabelecimento, somando as açôes realizadas previamente pela Pousada Sossego da Pampulha e as açôes realizadas durante e posteriormente ao estudo de caso em questão. Acontecimento este, importante para a futura participaçáo do estabelecimento na certificação ambiental promovida pela Tripadvisor, a "Ecolíderes", a qual foi apresentada e sugerida à diretoria da pousada durante o estudo de caso.

\section{CONCLUSÃO}

Com este estudo observou-se um comportamento - lamentavelmente extensível à populaçáo brasileira, com poucas exceçôes - que leva à permissibilidade do agravamento de situaçóes negativas ao ambiente, desconsiderando o agravamento da relação custo-benefício que as soluçóes tardias exigem. Precisa-se promover a transformação do pensamento e cultura nas pessoas por meio da educação ambiental transformadora/crítica, a qual procura sensibilizar os indivíduos, fazendo-os se preocupar com o meio ambiente em todas as suas formas e assim buscar ser mais sustentáveis pensando nas geraçóes atuais e futuras e que estas mudanças atinjam o turismo sustentável e assim os meios de hospedagem.

Seguindo esta linha de raciocínio, conclui-se com o presente trabalho que é possível aplicar a sustentabilidade ambiental no setor hoteleiro e motivar os funcionários, fornecedores, parceiros e hóspedes a aderir às ideias e práticas sustentáveis, desde que haja comprometimento e educação ambiental contínua e transformadora no ambiente de trabalho e, extensivamente no lar, ambientes públicos e de descanso e lazer. No que diz respeito aos resíduos sólidos e a coleta seletiva, a localização e a infraestrutura da pousada estudada, apresenta todos os subsídios necessários para o descarte correto dos resíduos sólidos, uma vez que a administração da pousada investiu em lixeiras de coleta seletiva e a Superintendência de Limpeza Urbana de BH realiza a mesma, com o sistema de coleta porta a porta no bairro. 
Em se tratando de todos os resíduos sólidos usados e descartados no estabelecimento, a proposta de redução da geração de resíduos sólidos foi iniciada e percebida com a atitude pontual dos funcionários ao evitar utilizar copos descartáveis diariamente. Ainda sobre os resíduos sólidos, pode-se observar que a maioria deles possuem propriedades químicas que permitem a reciclagem e os que não podem ser reciclados, podem ser reaproveitados. Acrescentando-se ainda que a característica de ser ou não reciclável de um produto, é relativa, pois depende se no município ou regiáo há indústrias ou empresas que coletam, tratam, reciclam ou reaproveitam tal resíduo.

No que concerne à educaçáo ambiental, foi constatado que a mesma deve ser aplicada e multiplicada não apenas aos funcionários da pousada, mas também para todos os hóspedes, fornecedores, parceiros, comunidade e a todos os familiares de cada funcionário do estabelecimento. De modo geral, foi diagnosticado que as açóes desenvolvidas na pousada principalmente pelas palestras, colaboraram para a sensibilizaçáo e aprimoramento da percepção ambiental dos saberes dos funcionários quanto ao gerenciamento de resíduos sólidos. Sendo os maiores desafios encontrados para o gerenciamento de resíduos sólidos neste meio de hospedagem: manter o interesse e o envolvimento de todos, incluindo os proprietários, hóspedes e funcionários; transformar as ações sustentáveis como rotina no estabelecimento; e manter uma continuidade e periodicidade da capacitação por meio da reeducação.

Após as açôes de educação ambiental, realizadas pela autora, com ênfase no gerenciamento de resíduos sólidos, na pousada, espera-se que os proprietários e os funcionários deem continuidade a todas as experiências e açóes desenvolvidas durante este período. Uma vez que a cartilha e o manual de boas práticas no gerenciamento de resíduos sólidos foram criados especificamente para este estabelecimento. A proposta é que os conteúdos passados sejam assimilados e multiplicados para todos os locais, de forma que possa ser um hábito para todos e não uma obrigação. Além disto, as açóes e os documentos criados durante o estudo de caso colaboram para a boa imagem verde e sustentável do meio de hospedagem em questão.

Contudo, para que ocorra de fato a mudança de hábitos e pensamentos de cada funcionário, é necessário que as açôes propostas neste estudo sejam seguidas e que a educação ambiental continue sendo aplicada no estabelecimento, de forma contínua e transformadora e que se estendam também para os clientes, a começar pelos adesivos de orientação para a coleta seletiva nos quartos dos hóspedes, proposto pela autora e produzido em conjunto com o setor de marketing da pousada. Espera-se que cada pessoa, independente do seu grau de instrução e faixa etária, seja consciente e multiplicadora das ideias ecologicamente corretas.

\section{AGRADECIMENTOS}

Agradecemos a todas as pessoas que direta ou indiretamente contribuíram para a realização deste estudo e em especial à banca examinadora da defesa da monografia de pós-graduaçâo da aluna, à Universidade Aberta do Brasil, à Universidade de Santa Maria e aos revisores deste trabalho.

\section{REFERÊNCIAS}

ABNT. NBR ISO 14.001:2004. Sistemas da Gestão Ambiental - Requisitos com orientaçôes para uso. Rio de Janeiro, 2004.

ABNT NBR ISSO 10.004: 2004. Resíduos sólidos - classificação. Rio de Janeiro, 2004.

ABNT. NBR ISO 15.401:2006. Meios de hospedagem - Sistema de gestão da sustentabilidade - Requisitos. 2006

BRASIL, Lei no 6.938/1981. Política Nacional do Meio Ambiente. Disponível em: < http://www.planalto.gov.br/ccivil_03/leis/L6938.htm>. Acesso em: 02 mar. 2017.

BRASIL, Lei no 9.795/1999. Política Nacional de Educação Ambiental. Disponível em: <http://www.planalto.gov.br/ ccivil_03/leis/19795.htm>. Acesso em: 01 mar. 2017.

BRASIL, Lei no 12.305/2010. Política Nacional de Resíduos Sólidos. Disponível em: <http://www.planalto.gov.br/ccivil_03/_ato2007-2010/2010/lei/112305.htm>, acesso em: 02 mar. 2017. 
CARPI JUNIOR, S.; SILVA, A. C. A.; LINDER, C. E. Contribuição da percepçáo e educação ambiental à área de uso público da Floresta Estadual de Avaré-SP (Capítulo 6. p. 85-98). In: DIAS, L. S. (Org.). Educação ambiental em foco. 1ed. Tupã - SP: Associação Amigos da Natureza - ANAP, 2014, v. 1, p. 156-180

CARVALHO, S.; NAIME, R. e BLANCO, L. A. de O. Situação da gestão de resíduos no setor de hotelaria. Revista Nordestina de Ecoturismo. Aracaju, v.2, n.2, outubro, 2009. DOI: https://doi.org/10.6008/ESS19838344.2009.002.0001.

CHOU, C. -J. Hotels' environmental policies and employee personal environmental beliefs: Interactions and outcomes. Tourism Management. 2014; 40: p. 436-446. DOI: https://doi.org/10.1016/j.tourman.2013.08.001.

CONAMA no 275/2001. Estabelece o código de cores para os diferentes tipos de resíduos, a ser adotado na identificação de coletores e transportadores, bem como nas campanhas informativas para a coleta seletiva. Disponível em: http:// www.mma.gov.br/port/conama/legiabre.cfm?codlegi=273 , acesso em 10 de junho de 2017.

CORRÊA, L. B.; CORRÊA, E. K.; PERUCHIN, B.; FERRÃO, A. L. L. C.; GUIDONI, L. L. C. Sustentabilidade no Turismo: estudo da Gestão Ambiental em empreendimento hoteleiro da Região Sul do Brasil. Rosa dos Ventos - Turismo e Hospitalidade. 2014; v. 6, n. 4: p. 583-602. Disponível em: http://www.ucs.br/etc/revistas/index.php/rosadosventos/ article/view/2723/pdf_333

COSTA, M. F. O lixão de posse-goiás: impactos ambientais e a questão do lixo. Trabalho de conclusão de curso apresentado à Universidade de Brasília. Departamento de Geografia. Brasília. 2013.

DE ALENCAR S. O. M., e ROSSETTO, A. M. A visão dos gestores de empreendimentos de hospedagem certificados em sustentabilidade pela NBR 15401: 2006. Revista de Administração da Universidade Federal de Santa Maria. 2014; 7.3. DOI: $10.5902 / 198346598907$

DIAS-ANGELO, F.; JABBOUR, C. J. C.; CALDERARO, J. A. Greening the work force in Brazilian hotel: The role of environmental training. Work. 2014; V. 49, n. 3: p. 347-356. DOI: 10.3233/WOR-141873

DIAS, L. S.; MARQUES, M. D. e DIAS, L. S. Educação, Educação Ambiental, Percepção Ambiental e Educomunicação. Capítulo 1- pgs. 12 a 37. In: DIAS, L. S.; LEAL, A. C. e CARPI, S. J. (Org). Educação Ambiental: conceitos, metodologia e práticas. Tupã: ANAP, São Paulo/SP, 1ºdiçâo. 2016; p.187. 347. DOI 10.3233/WOR-141873.

GOOGLE MAPS. Localização Pousada Sossego da Pampulha. [2017]. Disponível em: https://www.google.com.br/ maps/place/Pousada+Sossego+da+Pampulha/@19.860985,43.9736176,16.13z/data=!4m5!3m4!1s0xa6905836709e4b:0 xa84ce673c760f8bb!8m2!3d19.860654!4d-43.97098, Acesso em 09 de julho de 2017.

GOVERNO DO BRASIL. ONU define 2017 como Ano Internacional do Turismo Sustentável. 2017. Disponível em: http://www.brasil.gov.br/turismo/2017/01/onu-define-2017-como-ano-internacional-do-turismo-sustentavel, acesso em: 11 set. 2017.

INMETRO. "Histórico dos certificados válidos". De empresas nacionais e estrangeiras dentro e fora do SBAC emitidos no período de 2012 a 2017. In: http://certifiq.inmetro.gov.br/Grafico/HistoricoCertificadosValidos, acesso em 13 de dezembro de 2017.

LAMAS, S. A. Gestão De Resíduos Sólidos Em Meios De Hospedagem: Diagnóstico Da Atuação De Hotéis Cariocas. In: II Simpósio Nacional sobre gestáo ambiental de empreendimentos turísticos em 11 a 13 de maio de $2015^{\mathrm{a}}$ [Internet]. Canela/RS. 2015. Disponível em: http://docplayer.com.br/2642547-Gestao-de-residus-solidos-em-meios-de-hospedagem-diagnostico-da-atuacao-de-hoteis-cariocas.html.

LAMAS, S. A. Gestão de Resíduos Sólidos em Meios de Hospedagem: Um Estudo de Caso do Projeto Lixo Mínimo do Hotel Bühler em Visconde de Mauá, RJ. Revista Rosa dos Ventos - Turismo e Hospitalidade. 2015b; n. 7, v.1: p. 147161, jan-mar. DOI: http://dx.doi.org/10.18226/21789061.v7iss1p147 
LIMA, G.F.C. Educação ambiental crítica: do socioambientalismo às sociedades sustentáveis Gustavo Ferreira da Costa Lima. Educação e Pesquisa, v. 35, n. 1, p. 145-163, jan./abr. 2009. Disponível em: http://www.redalyc.org/articulo. oa?id=29811383010

LIMA, C.S. e COSTA, A.J.S.T. A importância da educação ambiental para o sistema de coleta seletiva: Um estudo de caso em Curitiba. Rev. Geogr. Acadêmica. 2016; v. 10: p.129-137. Disponível em: https://revista.ufrr.br/rga/article/ download/3312/pdf

MACEDO, R. L. G.; Macedo S. B.; Venturin, N.; Andretta. V.; Azevedo, F. C. S. Pesquisas de percepção ambiental para o entendimento e direcionamento da conduta ecoturística em unidades de conservação. Disponível em http://www. physis.org.br/ecouc/Artigos/Artigo50.pdf., acesso em 10 de julho de 2017.

MINISTÉRIO DO TURISMO. Turismo e sustentabilidade - Orientações para prestadores de serviços turísticos. Brasília, Ministério do Turismo. 2016 Disponível em: http://www.turismo.gov.br/images/pdf/06_06_2016_mtur_guia_ turismo_sustentabilidade.pdf

MINISTÉRIO DO TURISMO. Sistema Brasileiro de Classificação de Meios de Hospedagem - Portaria n. 100 de 21/06/2011. Disponível em: http://www.classificacao.turismo.gov.br/MTUR-classificacao/mtur-site/Portaria. Acesso em: 02 abr. 2017.

ONUBR - NAÇÕES UNIDAS NO BRASIL. Principais fatos. Disponível em: https://nacoesunidas.org/pos2015/principais-fatos/, acesso em 15 de abril de 2018.

OTOMA, S.; HOANG, H.; HONG, H.; MIYAZAKI, I. DIAZ, R. A survey on municipal solid waste and residentes' awareness in Da Nang city, Vietnam. J. Mater Cycles Waste Manag. 2013; v. 15:187-194. DOI 10.1007/s10163-0120109-2.

PERUCHIN, B. Estudo dos aspectos ambientais e do gerenciamento dos resíduos sólidos de um empreendimento hoteleiro. Trabalho de conclusão de curso apresentado à Universidade Federal de Pelotas. Curso de Engenharia Ambiental e Sanitária. Pelotas, 2015.

POUSADA SOSSEGO DA PAMPULHA. Site disponível em: http://sossegodapampulha.com.br/, acesso em 23 de maio de 2017.

PRADO, I. L.; SANTOS, M. E. E. dos; FARIAS, M. V. M. ;e GRECHI, I. S. F. Sustentabilidade nos meios de hospedagem: um estudo das práticas desenvolvidas no município de Balneário Camboriú. In: Mostra Nacional de Iniciação Científica e Tecnológica Interdisciplinar nos dias 11 e 12 de novembro de 2015. Instituto Federal [Internet]. Disponível em: http://eventos.ifc.edu.br/wp-content/uploads/sites/5/2015/10/SUSTENTABILIDADE-NOS-MEIOS-DE-HOSPEDAGEM-um-estudo-das-pr\%C3\%A1ticas-desenvolvidas-no-munic\%C3\%ADpios-de Balne\%C3\%A1rio-Cambori\%C3\%BA.pdf

QUERINO, L.A.L.; PEREIRA, J.P.G. Geração de resíduos sólidos: A percepção da população de são sebastião de Lagoa de Roça, Paraíba. Revista Monografias Ambientais - REMOA. 2016; v. 15: p. 404-415. DOI:10.5902/22361308.

REIGOTA, M. A Educação Ambiental frente aos desafios apresentados pelos discursos contemporâneos sobre a natureza. Educação e Pesquisa, São Paulo. 2010. v.36, n.2, p. 539-553, maio/ago. http://dx.doi.org/10.1590/S151797022010000200008

SANTOS, R. dos e LEAL, A. Z. Educação Ambiental e Gestão Ambiental participativa. Capítulo 4 - pgs. 99 a 110. In: DIAS, L. S.; LEAL, A. C. e CARPI, S. J. (Org). Educação Ambiental: conceitos, metodologia e práticas. Tupã: ANAP, São Paulo/SP, 1o Edição. p. 187p. 2016.

SANTOS, R. A.; MATSCHUCK, T. C. A Sustentabilidade e a Cadeia Produtiva Hoteleira: Um Estudo de Caso no JW Marriott, Rio de Janeiro. Revista Turismo -Visão e Ação -Eletrônica, v.17, n. 2, p. 444-474, 2015. Doi: $10.14210 /$ rtva.v17n2.p444-474 
SILVA, R. S.; SOUZA, R. V.de.; ARAÚJO, M. F.; PEREIRA, R. da SILVA, e BARROS, F. E. F. Avaliação da gestão ambiental no setor hoteleiro: um estudo nos hotéis do extremo norte brasileiro. Revista da Faculdade de Administração e Economia. 2013; v. 4, n2: p. 249-271. DOI: http://dx.doi.org/10.15603/2176-9583/refae.v4n2p249-271

SINGH, N; CRANAGE, D. e LEE, S. Green strategies for hotel: Estimation of recycling benefits. International Journal of hospitality management. 2014; V.43, p. 13-22. https://doi.org/10.1016/j.ijhm.2014.07.006 